\title{
DIMENSÕES TEÓRICAS E EPISTEMOLÓGICAS DA COMPETÉNCIA INFORMACIONAL NA ÁFRICA SUBSAARIANA
}

\section{THEORETICAL AND EPISTEMOLOGICAL DIMENSIONS OF INFORMATION LITERACY}

\author{
Ilídio Lobato Ernesto Manhique \\ Helen de Castro Silva Casarin ${ }^{2}$
}

\begin{abstract}
RESUMO
A presente pesquisa teve como objetivo identificar as dimensões teóricas e epistemológicas que definem as pesquisas sobre a competência informacional no continente africano, com ênfase para a região da África subsaariana. Adotou a pesquisa bibliográfica para a fundamentação teórica sobre 0 objeto e a coleta de dados foi feita por meio de um levantamento bibliográfico na African Journals Online (AJOL), que constitui uma das maiores bases de dados de informação científica do continente africano. Os resultados desse levantamento indicam que há inserção incipiente e recente das pesquisas acerca desse tópico, cujos enfoques teóricos são influenciados pelos padrões e modelos de competência informacional desenvolvidos no exterior, em particular nos Estados Unidos. Conclui-se que seja necessário o desenvolvimento de práticas informacionais que estejam voltadas ao contexto local, como forma de contribuir para a aprendizagem significativa e desenvolvimento da consciência crítica dos sujeitos.
\end{abstract}

Palavras-chave: Competência informacional. Epistemologia. AJOL. África Subsaariana.

\begin{abstract}
This research aimed to identify the theoretical and epistemological dimensions of information literacy in sub-Saharan Africa. It adopted bibliographic research for theoretical construction about the subject and the collecting data was carried out through bibliographic survey in African Journals Online (AJOL), which is one of the biggest databases of scientific information in Africa. The results show that there is incipient integration of researches about this subject, whose theoretical underpinnings are influenced by standards and models produced in international level. There is no evidence that indicates that African researchers use local or national frameworks to underpin their researches and information practices. It concludes that there is a need of new approach that incorporates information practices based on local context, as a way to foment meaningful learning and critical consciousness.
\end{abstract}

Keywords: Information literacy. Epistemology. AJOL. Sub-Saharan Africa.

Artigo recebido em 16/01/2019 e aceito para publicação em 10/05/2019.

1 Mestrado em Ciência da Informação pela Universidade Federal da Bahia, Brasil. Doutorando no Programa de Pós-Graduação em Ciência da Informação da Universidade Estadual Paulista Julio de Mesquita Filho, Brasil. Professor da Escola Superior de Jornalismo, Moçambique.E-mail: ilidiolobato@gmail.com.

2 Doutora em Letras pela Universidade Estadual Paulista Júlio de Mesquita Filho, Brasil. Docente permanente do Programa de Pós-Graduação em Ciência da Informação da Universidade Estadual Paulista Julio de Mesquita Filho, Brasil. E-mail: helen.casarin@gmail.com. 


\section{INTRODUÇÃO}

Na sociedade contemporânea, em que vivenciamos as inovaç̧ões tecnológicas, a confluência de tecnologias e 0 aumento do volume de dados e da informação, a competência informacional se tornou em um dos pilares fundamentais de sobrevivência por meio da aprendizagem permanente e contínua.

Esse é um dos motivos que tem mobilizado várias entidades internacionais, instituições acadêmicas, bibliotecários, entre outros, a advogarem sobre a necessidade de se transformar a competência informacional como uma aprendizagem transversal necessária em todos os ciclos de vida.

As contribuições de organismos como American Library Association (ALA) sobre a integração da competência informacional no contexto educacional têm ajudado na estruturação de programas instrucionais de bibliotecas, não só nos Estados Unidos, como também, em vários países do mundo, incluindo os africanos. Esses esforços têm sido acompanhados por uma densidade de pesquisas sobre a temática, em particular, nas áreas da Biblioteconomia e da Ciência da Informação, que têm trazido novos desdobramentos para a educação da competência informacional.

Apesar da aparente profusão de pesquisas sobre a temática no contexto global, a sua inserção no continente africano é, ainda, recente, considerando, também, a pouca abundância de programas de Ciência da Informação nesse continente. A maioria das pesquisas desenvolvidas têm como foco a automação de bibliotecas, utilização de tecnologias de informação, acesso às plataformas digitais e eletrônicas de informação científica e inclusão digital.

Sendo a competência informacional uma temática com mais de quatro décadas, consideramos que ela tem sido, historicamente, afetada pelas várias abordagens teóricas e epistemológicas que perpassam pela Ciência da Informação. Esta pesquisa adota os pressupostos da competência informacional crítica ou critical information literacy (SIMMONS, 2005; ELMBORG, 2006; TEWELL, 2015), que é uma corrente que estuda a competência informacional como uma prática sociocultural.

Inspirada nos princípios da pedagogia crítica de Paulo Freire, os seus defensores entendem que o estudo da competência informacional não se deve limitar à aplicação prescritiva de padrões e modelos já existentes, mas ser encarada como um processo que contribui para potencializar a consciência crítica e a aprendizagem significativa dos sujeitos. 
Perante o cenário de incipiência de pesquisas no continente africano, aliado às características específicas de diversidade sociolinguística, carência de recursos materiais e poucos profissionais qualificados para a promoverem a competência informacional, surgiram as seguintes indagações: Que abordagens teóricas e/ou epistemológicas embasam as pesquisas sobre essa temática em África? Quais são os autores que se destacam nas pesquisas sobre a competência informacional nesse contexto? Qual é o país de sua afiliação institucional?

0 corpus da pesquisa foi constituído por artigos de periódicos indexados na African Journals Online (AJOL), que é uma das maiores bases de dados de informação científica do continente africano. Na data da coleta (Novembro de 2018), esta base de dados agregava 523 periódicos de 32 países da África Subsaariana, dos quais mais de metade são de acesso aberto.

Deste modo, identificam-se os artigos científicos produzidos em África, registrados na AJOL, cujas pesquisas se relacionam com a competência informacional. A análise teve em consideração as bases epistemológicas da Ciência da Informação que serão descritas na seção seguinte.

\section{CIÊNCIA DA INFORMAÇÃO E COMPETÊNCIA INFORMACIONAL}

Nos princípios que sustentam a ciência pós-moderna existe 0 consenso de que as verdades científicas não são absolutas, e que o conhecimento e os postulados científicos são efêmeros, considerando o fato de serem contestáveis e, por isso, instáveis.

Esses aspectos introduzem a percepção de que o pensamento é conjuntural, o que retoma a noção de paradigma de Kuhn (1997), segundo a qual, o caráter transitório da verdade científica verifica-se quando as teorias, conhecimentos, valores e métodos aceitos por uma determinada comunidade científica entram em crise e dão lugar a uma revolução científica. Isto é, os aspectos que caracterizam a "ciência normal” são desafiados por uma nova ordem científica que se sobrepõe à anterior.

Considerando a Ciência da Informação um campo ainda em construção, em que os seus princípios, as teorias, os postulados e abordagens estão, ainda, em processo de consolidação, recomenda-se que haja ponderação ao estudar o campo sob prisma de paradigmas. Esse entendimento encontra respaldo em Wersig (1993), que sugere que as abordagens desenvolvidas na Cl ainda não revelaram transformações que indiquem uma revolução científica. Pelo contrário, tais abordagens têm sido utilizadas de forma complementar para a construção de uma epistemologia da área. 
No entanto, o que não se questiona é que a $\mathrm{Cl}$, assim como outros campos transdisciplinares e interdisciplinares, foi profundamente afetada pelas transformações paradigmáticas que ocorreram na segunda metade do século passado. Essas metamorfoses científicas foram responsáveis pelas primeiras tentativas de estabelecimento de uma epistemologia que orientasse as práticas científicas do campo.

Para Rabello (2012), o fundamento das discussões de uma epistemologia da Ciência da Informação está intrinsecamente ligado às narrativas históricas que contribuíram para a constituição do campo, em particular, a sua relação interdisciplinar com outras áreas do saber, a explosão informacional e as inovações no campo das tecnologias de informação e comunicação.

Esse entendimento já havia sido explorado por Capurro (2003), para quem não se pode dissociar a epistemologia da Ciência da Informação da sua complexa relação com a história do campo. Reconstituindo a evolução histórica desta área de conhecimento desde a sua emergência como disciplina específica. Outrossim, este autor evidencia a presença de três paradigmas que favorecem a sua compreensão epistemológica.

0 primeiro é o paradigma físico, que se relaciona com a teoria matemática da comunicação de Shannon e Weaver e à Cibercultura de Norbert Wiener. Esta visão reflete as tendências teóricas que dominaram a Ciência da Informação em sua fase embrionária como disciplina científica, com particular destaque para a teoria matemática da comunicação de Shannon e Weaver, que define a informação (mensagem) como algo independente da intervenção cognitiva dos sujeitos. Esta teoria não se preocupa com os aspectos humanos de produção e apropriação da informação, mas com o fator determinístico que as fontes e os sistemas de informação exercem, o que pode ser descrito como uma abordagem centrada nos sistemas.

Os limites dessa teoria concorreram para a emergência de um paradigma oposto - o cognitivo (CAPURRO, 2007) ou alternativo (DERVIN; NILAN, 1986) - em que a informação é entendida como uma construção individual dos sujeitos, sem considerar a relevância que os aspectos sociais e culturais têm nos processos de construção de sentido.

Foram estas limitações do cognitivismo que fizeram emergir um terceiro paradigma da Ciência da Informação - o paradigma social (CAPURR0, 2007) ou sociocognitivo (HJØRLAND, 2002, 2007). Ao assumir que o conhecimento resulta da interação do homem como o meio sociocultural circundante, a perspectiva sociocognitiva dissolve a concepção individual do conhecimento que 
dominou a Ciência da Informação durante a década de 1980 (DERVIN; NILAN, 1986; CAPURRO, 2003; HJØRLAND, 2004).

Hjørland e Albrechtsen (1995) desenvolveram uma abordagem na Ciência da Informação baseada no sociocognitivismo que ficou conhecida como domain analysis, que propõe que os estudos dos campos devem estar sempre relacionados às práticas específicas das comunidades discursivas, entendidas como "[...] distintos grupos sociais sincronizados em pensamento, linguagem e conhecimento, constituintes da sociedade moderna" (NASCIMENTO; MARTELETO, 2004, p. 1).

No entanto, corroboramos com o posicionamento de Rabello (2012, p. 21), segundo o qual:

A ideia de paradigma, a partir das três categorias, pode ser problematizada diante do fato de que na passagem de um paradigma a outro - do paradigma normal ao extraordinário e deste à nova ciência - ocorre a sobrevalorização e a sobreposição da inovação frente à tradição teórica. Nesse sentido, questiona-se se no caso da Cl realmente existe uma superação sucessiva entre os supostos "paradigmas" objetivo, subjetivo e social.

Desta forma, interessa-nos destacar que a exposição da Ciência da Informação em torno dos três paradigmas acima mencionados não significa, necessariamente, que o campo caminha numa trajetória histórica linear, pois, conforme Capurro (2003, p. 3) "[...] muitas teorias se entrecruzam com intensidade distinta em diversos períodos [...]" e se não houver uma compreensão holística, estas divisões serão sumamente arbitrárias.

Nesta pesquisa adotamos essa descrição com finalidade meramente didática, na medida em que nos permite compreender que processos nortearam o desenvolvimento da Ciência da Informação, as abordagens dominantes em cada época histórica, incluindo as variantes sociais, políticas e econômicas que influenciaram a evolução do campo.

A competência informacional como domínio de estudos da Ciência da Informação não escapa a estas transfigurações históricas do campo, visto que as suas abordagens são, também, influenciadas pelos diversos "paradigmas" que perpassam pelo campo. Considerando a abordagem sociocognitiva (HJøRLAND, 2002; 2004) ou paradigma social (CAPURRO, 2003) que enfoca nas determinações contextuais nos processos cognitivos de construção de significados e de aprendizagem, assume-se que as bases teóricas e o âmbito de aplicação da competência informacional devem ser ajustados às dinâmicas do contexto socioeconômico e político, de forma que a aprendizagem fomentada contribua para potencializar a consciência crítica. 
No que tange ao continente africano, a competência informacional é um campo de estudos em fase de afirmação, buscando, ainda, estabelecer os seus preceitos teóricos, conceituais, incluindo as formas de sua aplicação no universo educacional, particularmente no contexto das bibliotecas escolares e universitárias. São poucos os países africanos que desenvolveram modelos locais de competência informacional, sendo a África do Sul um dos poucos casos, que, por meio do Committee for Higher Education Librarians of South Africa (CHELSA), criou um frameworknacional para Information Literacy Training (ILT) (ESTERHUIZEN; KUHN, 2010).

Esta pesquisa assume os pressupostos da competência informacional crítica (ELMBORG, 2006; SIMMONS, 2005; TEWELL, 2015), segundo os quais, as práticas educacionais voltadas ao fomento da competência informacional não se devem limitar aos padrões e modelos existentes. Elas devem ser encaradas como um processo de aprendizagem cuja finalidade é contribuir para potencializar a consciência crítica dos sujeitos.

\section{METODOLOGIA}

Esta pesquisa é de natureza descritiva e adota as abordagens qualitativa e quantitativa. Teve como objetivo analisar as dimensões teóricas e epistemológicas dos estudos da competência informacional no continente africano, com enfoque na África subsaariana. Importa frisar que os aspectos epistemológicos e críticos fazem parte das onze abordagens de análise de domínio, que permitem compreender as condições pelas quais o conhecimento se constrói e se socializa dentro das comunidades discursivas (HJØRLAND, 2002; GUIMARÃES, 2014).

Hjørland $(2002,2018)$ sugere que cada abordagem seja combinada com outras para alcançar a profundidade e complexidade do domínio. Assim, os estudos epistemológicos e críticos foram combinados com os estudos históricos, para a compreensão da evolução teórica e terminológica da competência informacional, bem como as análises bibliométricas, visando estabelecer as relações entre os pesquisadores dentro deste campo de estudos.

0 corpus da pesquisa foi constituído por artigos de periódicos indexados na AJOL, uma das maiores bases de dados de informação científica da região subsaariana do continente. Na data da coleta (Novembro de 2018), esta base englobava 523 periódicos disciplinares e multidisciplinares de 32 países da África subsaariana, dentre os quais a maioria são da Nigéria (222), África do Sul (96) e Etiópia (30). Entre os países africanos de língua oficial portuguesa, consta, apenas, Moçambique com um único periódico indexado. 
Considerando que todos os periódicos veiculam o conhecimento na língua inglesa, 0 levantamento bibliográfico foi feito por meio da expressão padrão “information literacy" e recuperou 211 artigos. Após a análise pelo Título, Resumo e Palavras-chaves (Title, Abs, Key Words), a quantidade reduziu para 34 (trinta e quatro) artigos (APÊNDICE 1). Os demais artigos foram descartados porque versavam sobre outras temáticas, tais como inclusão digital, acesso à informação, digital literacy e a expressão information literacy aparecia de forma "marginal".

Para a inferência sobre os aportes teóricos e epistemológicos foram analisados os resumos, as palavras-chaves e, parcialmente, as seções do texto. Os resumos e as palavras-chave, pelo seu caráter informativo oferecem a ideia geral dos aportes adotados.

Para caracterizar a estrutura intelectual deste domínio foram utilizadas as análises de bibliométricas com o propósito de identificar os autores mais produtivos, os periódicos e os países que mais publicam sobre a temática. Com base na análise de conteúdo, foram identificadas três categorias de análise que serão, detalhadamente, discutidas na próxima seção deste trabalho.

\section{APRESENTAÇÃO E DISCUSSÃO DOS RESULTADOS}

A apresentação e discussão dos resultados têm como base as seguintes categorias de análise: na primeira discutem-se os aspectos bibliométricos das pesquisas de competência informacional na África, destacando questões relacionadas aos autores mais produtivos, sua origem, incluindo os periódicos que mais veiculam publicações sobre esta temática. A segunda trata das influências teóricas que embasam as pesquisas de competência informacional relatadas nos artigos analisados. Na terceira e última, discute-se, a partir dos fundamentos da Ciência da Informação, a natureza epistemológica que fundamenta estes estudos no continente africano.

\subsection{Aspectos bibliométricos}

Esta investigação traz algumas evidências sobre a inserção da competência informacional em pesquisas da Ciência da Informação no continente africano. A primeira inferência diz respeito à quantidade reduzida de 34 artigos publicados entre 2002 a 2018 que tratam, especificamente, dessa temática, publicados nos periódicos africanos indexados na AJOL. Essa constatação sugere que a 
competência informacional, enquanto objeto de pesquisa, ainda está em processo de afirmação e/ou consolidação na Ciência da Informação africana.

Esse fato tem também como evidência a inserção recente desta temática no universo da Ciência da Informação africano, considerando que o artigo mais antigo recuperado na AJOL ter sido publicado em 2002, pela pesquisadora Kikky Haberle, da África do Sul, ou seja, quase três décadas depois de Paul Zurkowski ter introduzido o termo nos Estados Unidos.

0 Gráfico 1 ilustra a distribuição dos artigos publicados entre 2002 e 2018. Como se pode verificar, 2017 foi 0 ano em que houve mais publicações, em um total de cinco artigos. Ao passo que nos anos de 2007 e 2003 não houve publicações sobre a temática em análise no conjunto de periódicos indexados na base de dados AJOL.

Gráfico 1 - Distribuição dos artigos sobre Information literacy entre 2002 e 2018

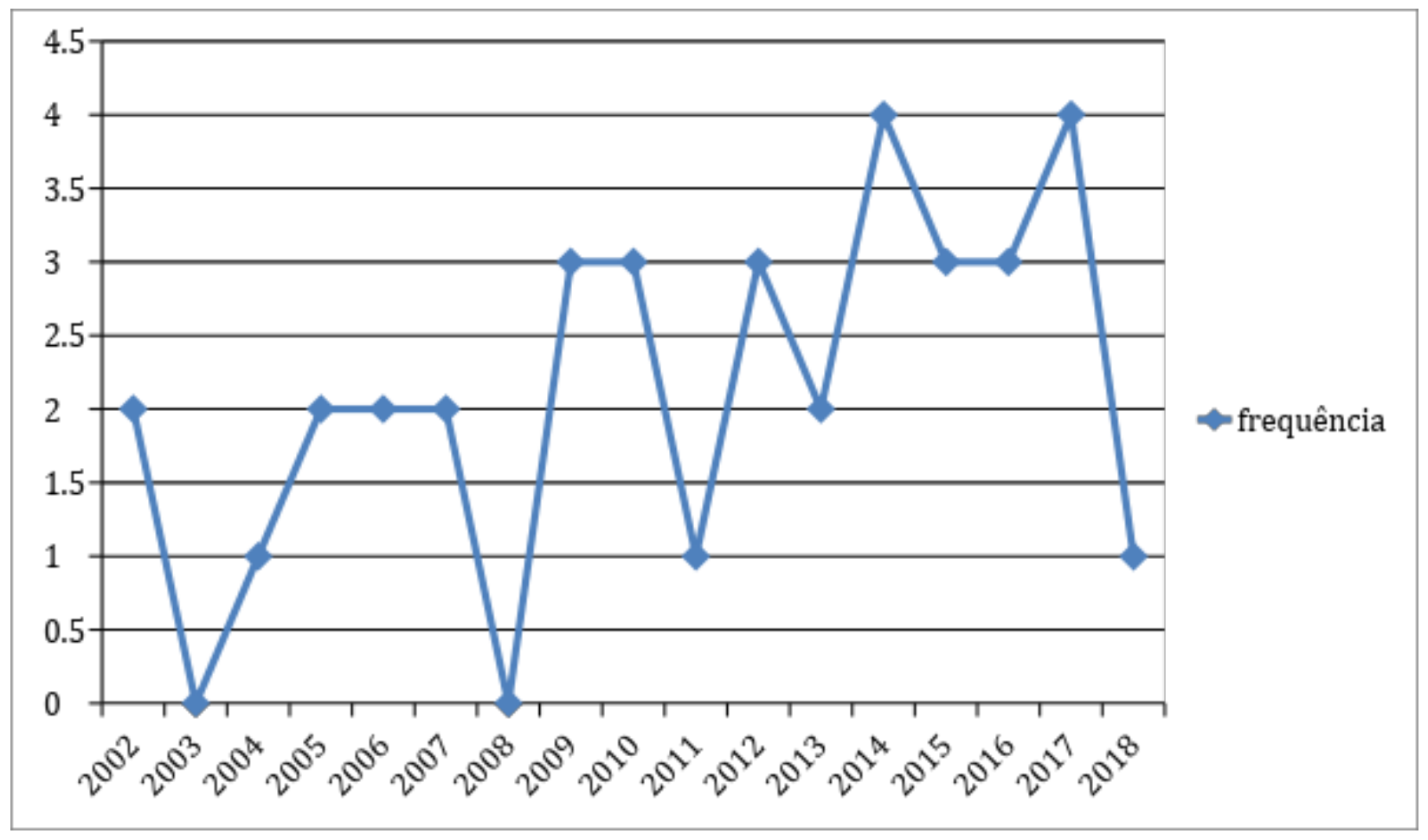

Fonte: Elaborado pelos autores

Vale ressaltar que esta constatação reflete somente os dados coletados nessa base de dados AJOL, tendo em consideração que ela não incorpora todos os periódicos africanos e, sobretudo, não inclui nenhum periódico da África do Norte, que é uma região com uma larga história na Ciência da Informação e, em particular, nos estudos da competência informacional. 
Nessa base de dados, também, não estão representados todos os periódicos da África do Sul, que é um dos países tem um dos movimentos mais atuantes de competência informacional no continente.

No que tange à produção por autor, não foi possível identificar uma elite de pesquisadores que se dedicam, especificamente, a esta temática. No domínio dos estudos bibliométricos, a produtividade dos autores é explicada por meio da Lei de Lotka, segundo a qual um número reduzido de autores detém a maioria da produção intelectual de um campo científico (ARAÚJO, 2016). Não obstante esses fundamentos, nesta pesquisa constatou-se uma dispersão acentuada de autores que publicam sobre a temática.

Com o desdobramento da autoria múltipla, as 34 (trinta e quatro) publicações recuperadas tiveram a contribuição de 50 (cinquenta) autores, sendo que nenhum deles teve mais do que duas publicações, conforme demonstra a tabela 1.

Tabela 1 - Autores mais produtivos

\begin{tabular}{l|c|c|c|c}
\hline \multicolumn{1}{c|}{ Autores } & $\begin{array}{c}\text { Número de } \\
\text { publicações }\end{array}$ & $\begin{array}{c}\text { Autoria } \\
\text { individual }\end{array}$ & Co-autoria & Origem \\
\hline KUHN, Rosemery & 2 & 1 & 1 & África do Sul \\
LAVAL, Mohammad & 2 & 1 & 1 & Nigéria \\
OBASUYI, Luke & 2 & 0 & 2 & Nigéria \\
BANNERMAN, V. J. & 2 & 2 & 0 & Gana \\
\hline
\end{tabular}

Fonte: Elaborado pelos autores

Geralmente, este tipo de dispersão é comum quando as temáticas ainda não tenham grande penetração em um determinado campo ou em uma comunidade científica.

Dos 34 registros recuperados nessa base de dados, a maioria tem sido em co-autoria, sendo que apenas treze foram publicados em autoria individual. Dentre os autores com mais do que uma publicação, quatro tiverem, pelo menos, uma publicação em autoria individual.

A maioria dos autores das publicações analisadas tem a sua afiliação em instituições acadêmicas da Nigéria, agregando um total de 34 autores, isto é, mais de $60 \%$ de pesquisadores que publicam sobre a temática nos periódicos indexados na AJOL. Os demais países representados nesta estrutura são: a África do Sul, o Gana, o Uganda, o Botsuana, a Tanzânia e o Quênia (Gráfico 2). Nesse levantamento não foi recuperada nenhuma pesquisa proveniente de pesquisadores africanos de países de língua portuguesa, o que demonstra a inserção incipiente desta temática nesse contexto. 
Gráfico 2 - Publicações por país

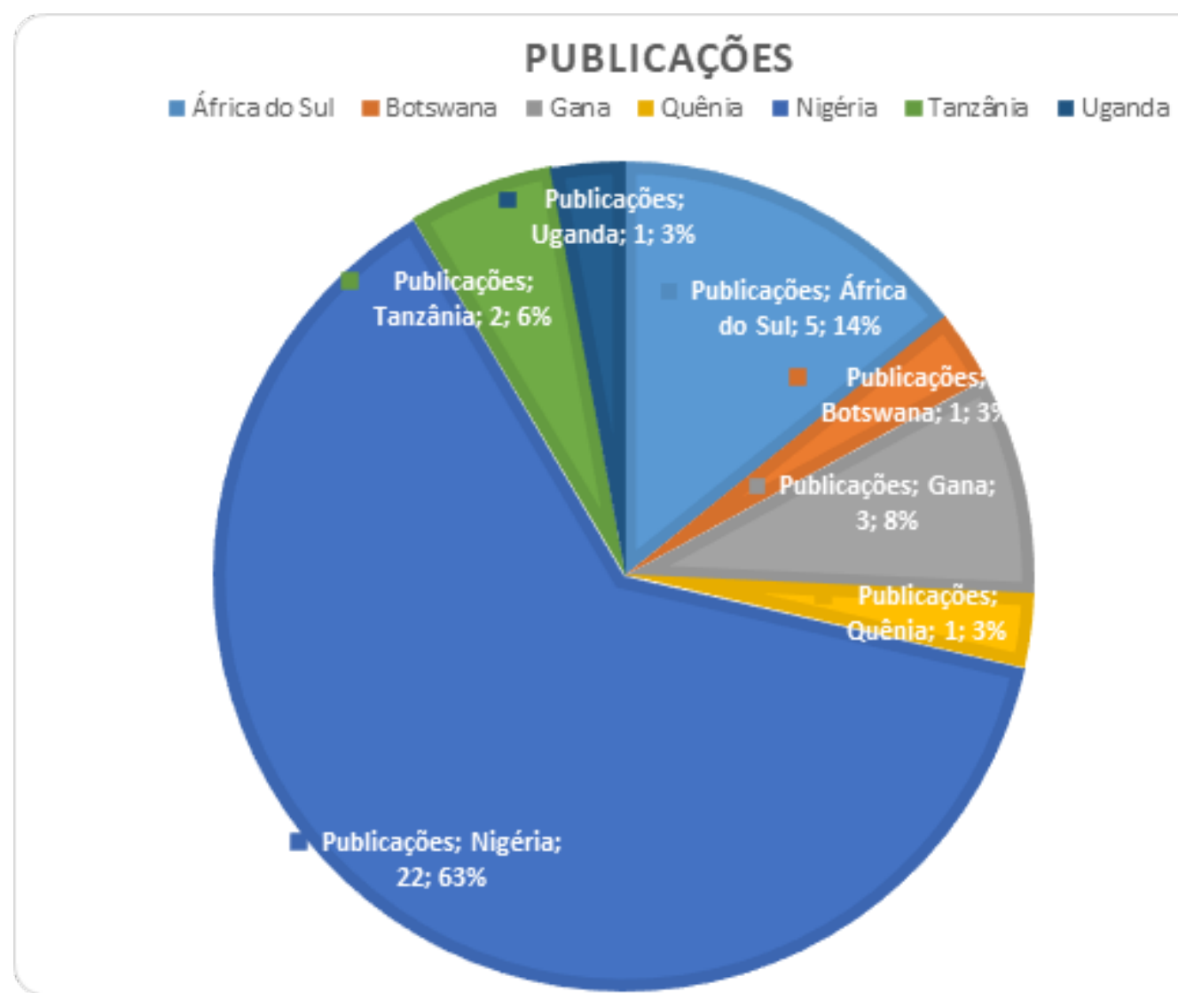

Fonte: Elaborado pelos autores

Este gráfico reforça a conclusão de que estes estudos ainda estão em processo de inserção na Ciência da Informação dos países africanos, considerando a concentração de autores num único país, assim como a número reduzido de autores que se dedicam a essa temática.

A posição destacada da Nigéria pode estar associada ao fato de a maioria dos periódicos indexados nesta base serem originários deste país, assim como os que contemplam o tópico da competência informacional ser proveniente daquele país. A pesquisa identificou 13 (treze) periódicos, dos quais sete pertencem a instituições acadêmicas da Nigéria, conforme evidencia a tabela 2. 
Tabela 2 - Periódicos africanos com publicações de competência informacional

\begin{tabular}{|l|c|c|}
\hline \multicolumn{1}{|c|}{ Periódico } & $\begin{array}{c}\text { No artigos } \\
\text { publicados }\end{array}$ & País de origem \\
\hline African Journal of Library Archives \& Information Science & 01 & Botswana \\
\hline Ghana Library Journal & 03 & Gana \\
\hline Global journal of educational research & 01 & Nigéria \\
\hline $\begin{array}{l}\text { Information Impact: Journal of Information and Knowledge } \\
\text { Management }\end{array}$ & 07 & Nigéria \\
\hline Information Technologist (The) & 06 & Nigéria \\
\hline Innovation & 04 & África do Sul \\
\hline Journal of Hum \& Soc Sci & 01 & Quênia \\
\hline Lagos Journal of Library and Information Science & 01 & Nigéria \\
\hline Nigerian Libraries & 01 & Nigéria \\
\hline Nigerian School Library Journal & 02 & Nigéria \\
\hline South African Journal of Higher Education & 01 & África do Sul \\
\hline The Information Manager & 03 & Nigéria \\
\hline University of Dar es Salaam Library Journal & 03 & Tanzânia \\
\hline Total & 34 & \\
\hline
\end{tabular}

Fonte: Elaborado pelos autores

A posição destacada da Nigéria pode ser associada ao fato de ser o país com maior tradição de estudos em Ciência Informação em África. Segundo Gupta (1997), os primeiros cursos formais em Biblioteconomia e Ciência da Informação surgiram na Nigéria, em 1959, por meio de esforços da tradicional Universidade de Ibadan. Hoje, este país concentra a maioria dos cursos ligados à Ciência da Informação em todos os ciclos da educação superior, nomeadamente, a graduação e a pós-graduação.

\subsection{Tendências teóricas}

A pesquisa revelou várias tendências teóricas da competência informacional. No entanto, o mais dominante perfil teórico das pesquisas de competência informacional está relacionado à influência conceitual da American Library Association (ALA) e nos padrões de ACRL (2000) para o ensino superior. Embora este organismo tenha feito uma revisão dos seus Standards, tendo introduzido os frameworks de competência informacional (2015), o nosso levantamento não identificou nenhuma pesquisa que tenha embasamento neste novo quadro teórico-conceitual.

Essa constatação pode estar relacionada a dois aspectos: i) uma relativa estagnação teórica ou ii) 0 desconhecimento desses frameworks, considerando a sua natureza recente.

A partir da análise dos trabalhos recuperados, apresentam-se quatro grupos de abordagens teóricas que embasam as pesquisas de competência informacional no continente africano (Quadro 1). 
Quadro 1 - Categorias teóricas e epistemológicas da competência informacional em África

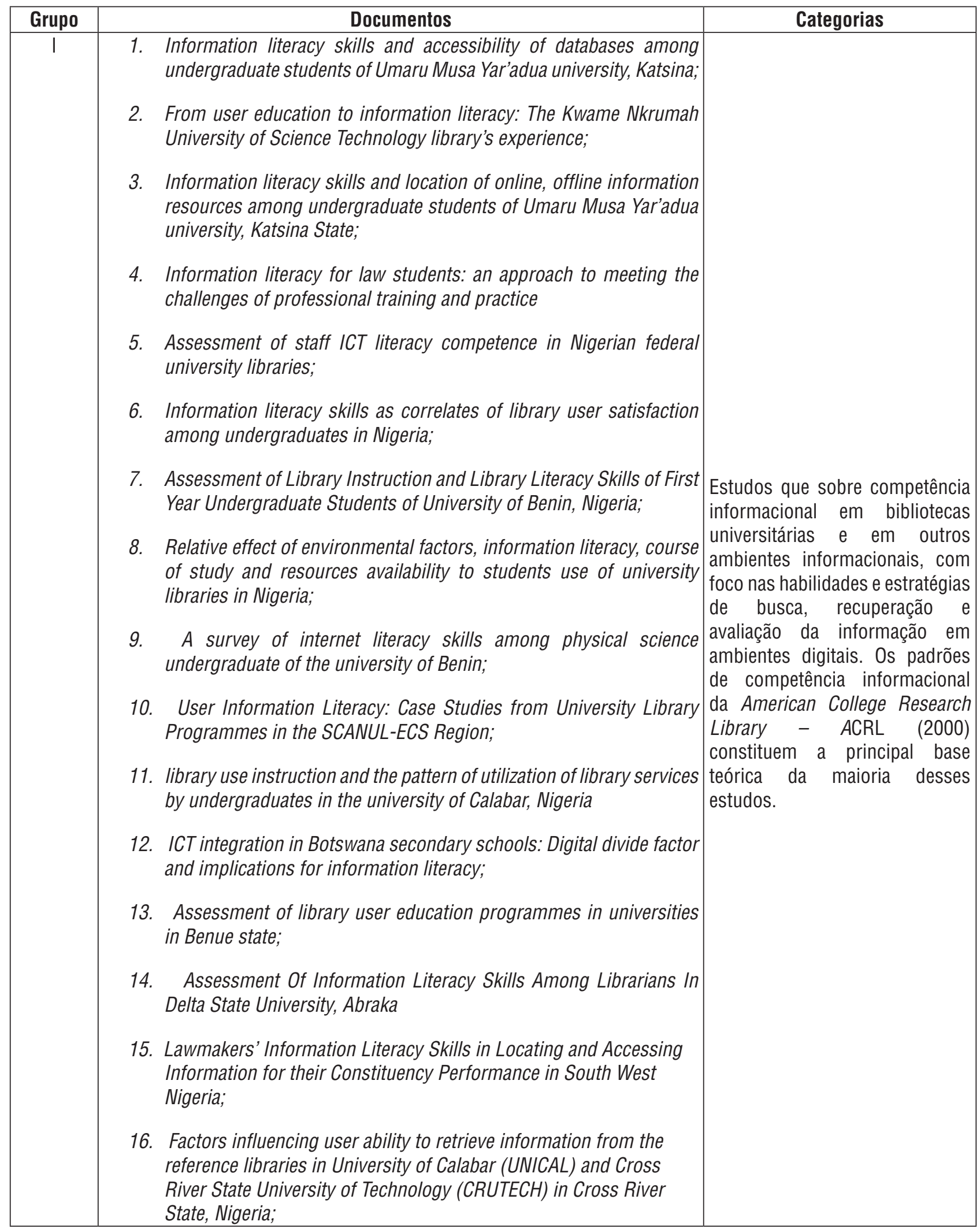




\begin{tabular}{|c|c|c|}
\hline II & $\begin{array}{l}\text { 1. Information literacy programs and early childhood education as a } \\
\text { means to achieving sustainable development goal 4: Any nexus for } \\
\text { librarianship?; } \\
\text { 2. Information Literacy Competencies for School Librarian; } \\
\text { 3. Lecturers' perception of students' information literacy skills versus } \\
\text { students' actual information literacy levels } \\
\text { 4. Transforming Nigeria undergraduate training through information } \\
\text { competency; } \\
\text { 5. School library development and an understanding of information } \\
\text { literacy competencies among secondary school students in Nigeria }\end{array}$ & \begin{tabular}{|l} 
Pesquisas que relatam a \\
integração da \\
informacional em bibliotecas \\
escolares de vários países \\
africanos. O foco desses \\
estudos consiste na avaliação \\
dos programas de competência \\
informacional e das habilidades \\
desenvolvidas pelos alunos. \\
Nota-se a influência teórica dos \\
padrões da American Association \\
School Library (AASL, 2007), \\
sobre a função educação das \\
bibliotecas escolares.
\end{tabular} \\
\hline III & $\begin{array}{l}\text { 1. Literacy education and the roles of Nigerian libraries and librarians; } \\
\text { 2. Knowing is not enough: Engaging in the Knowledge Economy; } \\
\text { 3. The Critical Role Of Libraries In The Information Society; } \\
\text { 4. Library and Librarians In Information Literacy for Lifelong Learning } \\
\text { in University Education; } \\
\text { 5. Library service delivery, information literacy knowledge: a modelling } \\
\text { factor for societal growth. } \\
\text { 6. 21st century librarians and effective information service; }\end{array}$ & $\begin{array}{l}\text { Estudos teóricos que explicitam } \\
\text { as abordagens da competência } \\
\text { informacional, incluindo a sua } \\
\text { relação com a aprendizagem } \\
\text { e } \quad 0 \quad \text { desenvolvimento } \\
\text { socioeconômico na sociedade } \\
\text { contemporânea. Destacam o } \\
\text { papel das bibliotecas como } \\
\text { ambientes responsáveis pelo } \\
\text { fomento dessa aprendizagem. }\end{array}$ \\
\hline IV & $\begin{array}{l}\text { 1. Information Literacy (IL) learning experiences: A literature review; } \\
\text { 2. Developing a theoretical evaluative framework for information } \\
\text { literacy interventions: a South African initiative; } \\
\text { 3. Educators and public librarians: unwitting partners in the information } \\
\text { literacy education of South African youth? } \\
\text { 4. CHELSA draft guidelines on Information Literacy: paving the way to } \\
\text { a South African national framework } \\
\text { 5. Inter-sectoral approach to information literacy in Uganda; } \\
\text { 6. Information literacy training for teachers in a developing South } \\
\text { African context: suggestions for a multi-disciplinary planning } \\
\text { approach; } \\
\text { 7. Understanding information literacy }\end{array}$ & $\begin{array}{l}\text { Estudos que teóricos e } \\
\text { empíricos que apresentam } \\
\text { abordagens alternativas de } \\
\text { pesquisa da competência } \\
\text { informacional. Tais } \\
\text { pesquisas introduzem alguns } \\
\text { questionamentos aos modelos } \\
\text { e padrões de competência } \\
\text { informacional vigentes no } \\
\text { contexto internacional. Fazem } \\
\text { menção sobre a necessidade de } \\
\text { desenvolvimento de frameworks } \\
\text { que refletem a realidades } \\
\text { socioculturais específicas. }\end{array}$ \\
\hline
\end{tabular}

Fonte: Elaborado pelos autores

No que tange aos primeiros dois grupos, constata-se que a base teórica utilizada em vários estudos empíricos tem como sustentação os arquétipos de competência informacional estabelecidos nos Estados Unidos. Para além da primazia dos padrões ACRL (2000), há que ressaltar que existem outras influências teóricas americanas, em particular, os padrões de American Association School Library - AASL (2007), que identificam os parâmetros de aprendizagem da competência informacional no contexto escolar. 0 primeiro grupo concentra a maior parte dos trabalhos, 16 (dezesseis) ao todo. 
Eles estão centrados em bibliotecas universitárias, o que coincide com a literatura internacional, além disto nota-se que a partir de 2012 os trabalhos sobre este tema têm sido frequentes. A segunda categoria concentra cinco artigos e também concentra estudos empíricos mas em bibliotecas escolares.

Da análise realizada, não foi encontrada nenhuma evidência que indique a utilização institucionalizada de modelos autóctones, cuja finalidade fosse a efetiva integração da competência informacional, tanto no ensino superior, quanto na educação básica.

Essa constatação reforça os fundamentos da teoria crítica da competência informacional sobre a necessidade de uma abordagem alternativa que não seja, totalmente, enviesada pelo capitalismo neoliberal (SIMMONS, 2005; ELMBORG, 2006; TEWELL, 2015, 2018). Segundo Wang (2011), uma dessas alternativas seria a adoção de uma perspectiva de competência informacional pautada em pressupostos teóricos que incorporam a perspectiva sociocultural, considerando que esta fornece fundamentos para a uma aprendizagem situada e colaborativa.

Em número relativamente reduzido em relação às outras categorias, no Grupo III foram identificadas seis pesquisas que se dedicam ao aprofundamento e explicitação teórica da competência informacional no contexto internacional, sua importância para a educação na sociedade contemporânea, bem como o papel reservado às bibliotecas no fomento da aprendizagem permanente.

0 quarto grupo é constituído por sete pesquisas que trazem uma abordagem alternativa para os estudos da competência informacional no continente africano. Embora sem explicitação, verifica-se que a inclinação desses estudos à teoria crítica, visto que criticam a incorporação excessiva de modelos exógenos sem, muitas vezes, a devida adequação às condições locais de diversidade sociolinguística, de deficiente infraestrutura tecnológica, de analfabetismo digital e funcional e, também, de falta de profissionais de informação qualificados para a educação da competência informacional.

Para tal tomamos como respaldo as deliberações da Declaração de Praga (2005), que posiciona a competência informacional como o farol da sociedade da informação. Portanto, considerando que os desafios da sociedade da informação são diferentes, conforme as políticas de cada país e/ou região, então, torna-se problemática a ideia de que o ensino e a aprendizagem da competência informacional possam seguir postulados universais, embora alguns conteúdos sejam pertinentes independente do contexto.

Os estudos incluídos no grupo IV destacam a assunção de que é necessário que se compreendam as condições endógenas dos países africanos para que os parâmetros de competência informacional fomentados não estejam desarticulados dos objetivos de desenvolvimento local. 
Apesar dessas pesquisas não adotarem a expressão critical information literacy, os seus autores apresentam axiomas que sustentam a tese de que a competência informacional deve, inevitavelmente, contribuir para potencializar a consciência crítica dos indivíduos, cujas premissas estão explicitadas na "Pedagogia Crítica" de Paulo Freire.

Nesse grupo de pesquisas (IV), foi, igualmente, identificada uma pesquisa que tem como fundamento a abordagem fenomenográfica da competência informacional (HART, 2006, APÊNDICE 1). Esse foco teórico-metodológico segue a linha de estudos da pesquisadora australiana Christine Bruce, que foi responsável pelo ingresso desta perspectiva na Ciência da Informação. É uma abordagem que, segundo Limberg, Sundin e Talja (2012), adota a perspectiva de segunda-ordem (second-order perspective), cujo foco é o mapeamento das concepções dos indivíduos acerca de um fenômeno.

Finalizando, importa frisar que as pesquisas relatadas nos primeiros três grupos foram, na sua maioria, desenvolvidas por pesquisadores afiliados às instituições acadêmicas nigerianas. Em posição oposta, as pesquisas incluídas no grupo IV (crítica e fenomenográfica) foram desenvolvidas por pesquisadores da África do Sul. Essa diversidade teórica trazida por pesquisas oriundas deste país reforça a posição da África do Sul como o país com um dos movimentos mais atuantes de competência informacional que, decerto, acompanha as tendências internacionais e estimula a concepção de modelos locais para a educação da competência informacional.

\subsection{Dimensão epistemológica}

No âmbito epistemológico, foram identificadas as três tendências de pesquisa conforme a tipologia proposta pelo filósofo Rafael Capurro. Retomando ao quadro 1, os trabalhos que compõem os três primeiros grupos podem ser divididos em duas abordagens:

- $\quad$ Foco instrumental, considerando que as competências fomentadas estão no nível de utilização das tecnologias de informação e comunicação e no acesso às bases de dados e outras plataformas digitais. Capurro (2003) situa as abordagens cujo foco são as fontes e sistemas de informação no paradigma físico, que foi dominante na construção epistemológica da Ciência da Informação na fase inicial de seu surgimento como campo científico.

- $\quad$ Foco cognitivo, visto que os aportes teóricos adotados nessas pesquisas (ACRL, 2000; ASSL, 2007), identificam a informação e o conhecimento como resultado de uma construção que ocorre na esfera individual, sem interferência de fatores externos. Esse foco corrobora com o paradigma cognitivo da Ciência da Informação mencionado nas seções anteriores (CAPURRO, 2003; HJORLAND, 2004). 
Reforça-se essa constatação através da análise das palavras-chave (Figura 1), que evidenciam, particularmente, a ênfase instrumental e/ou tecnológica nas pesquisas e práticas de competência informacional no continente africano.

Figura 1 - Palavras-chave mais representativas nos artigos analisados

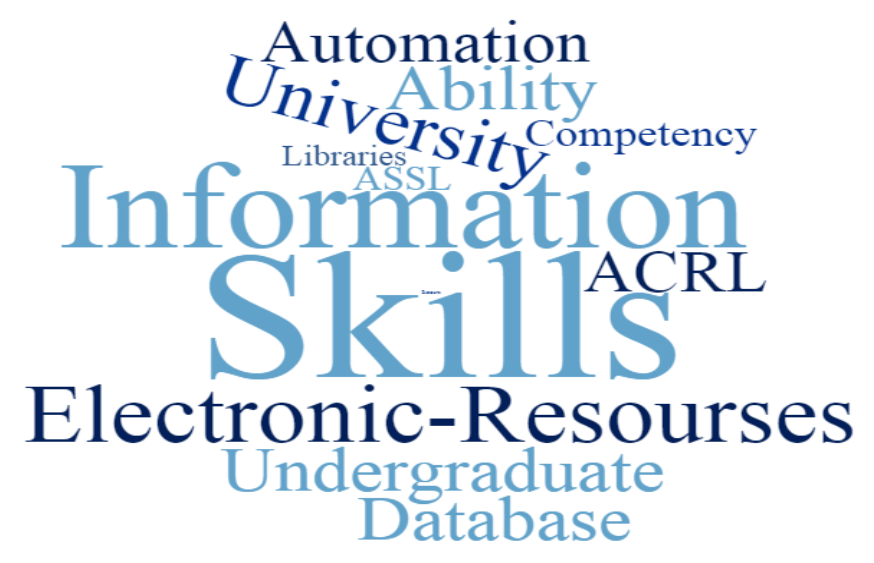

Fonte: Elaborado pelos autores

Por exemplo, a aderência de expressões como "habilidades, automação, recursos eletrônicos e bases de dados" reforçam o nível básico (URIBE TIRADO, 2014) ou concepção tecnológica (DUDZIAK, 2003), que caracterizam as práticas informacionais no continente africano. Esse foco epistemológico é, predominantemente, adotado por pesquisadores de instituições acadêmicas da Nigéria.

Em sentido contrário, a terceira tendência abrange o quarto grupo (Quadro 1), que adota a epistemologia social (CAPURRO, 2003) ou sociocognitiva (HJØRLAND, 2004), que define 0 conhecimento como um construto sociocultural.

Embora em quantidade menos expressiva, as palavras-chave (Figura 1) que definem esse gênero de pesquisas são: "learning" e "knowledge". Seguindo este enfoque ou paradigma social, a competência informacional é definida como uma forma de aprendizagem que é instigada pelas relações sociais que os indivíduos estabelecem entre si e com o meio. Este foco epistemológico é adotado por 
pesquisas da África do Sul que, conforme observado anteriormente, é o país com maior diversidade teórica nas pesquisas de competência informacional.

Em síntese, os trabalhos que compuseram o corpus desta pesquisa fornecem-nos dados que permitem concluir, embora de forma preliminar, que os estudos da competência informacional em África perpassam pelas principais abordagens que configuram a Ciência da Informação. No entanto, assume-se que para que se obtenha uma imagem mais completa seja necessário que novos estudos sejam feitos em outras bases de dados internacionais que indexam periódicos africanos da Ciência da Informação.

\section{CONSIDERAÇÕES FINAIS}

A pesquisa teve como objetivo identificar as tendências teóricas e epistemológicas dos estudos da competência informacional na Ciência da Informação africana. A primeira constatação reside na inserção recente desta temática entre os pesquisadores africanos, avaliando pela quantidade reduzida de artigos publicados numa das maiores bases de dados de informação científica da África subsaariana. Esse aspecto é complementado pelo fato de não haver, ainda, frentes de pesquisa que dominam estes estudos, visto que entre os autores que mais publicam sobre a temática têm, no máximo, duas publicações.

Outro aspecto que se destaca é a concentração de pesquisas sobre a competência informacional em poucos países, com destaque para a Nigéria que concentra mais de metade das publicações recuperadas na base de dados da qual foi constituído o corpus da pesquisa. A Nigéria destaca-se, também, nos autores com maior número de publicações e na quantidade de periódicos que publicam sobre a temática.

Não obstante, há que relativizar estes dados, tendo em conta que este país tem o maior número de periódicos indexados nessa base. Por outro lado, há que considerar o fato de vários periódicos de referência da África do Sul, indexados em outras bases de dados internacionais não estarem incorporados na AJOL. Portanto, estudos mais holísticos em outras bases de dados internacionais podem trazer uma imagem mais completa sobre como os pesquisadores africanos pensam a competência informacional.

No que tange às bases teóricas, constatou-se, em grande escala, pesquisas que têm como foco o mapeamento das competências informacionais no ensino superior, adotando um dos modelos mais utilizados internacionalmente - os padrões de competência informacional da ACRL. Isto revela, 
de fato, a importância que este organismo teve e continua tendo para o surgimento de movimentos de competência informacional no âmbito global.

Outro grupo destaca a necessidade de promoção da competência informacional tendo em conta os aspectos sociais e culturais de cada contexto. Ou seja, defendem a inevitabilidade de se pensar a competência informacional como parte de uma aprendizagem situada, que contribua para a elevação da consciência crítica dos aprendizes. Embora os autores desses trabalhos não explicitem as abordagens adotadas, podemos inferir que se trata, por um lado, da perspectiva sociocultural e da fenomenográfica, por outro. Ambas foram desenvolvidas por pesquisadores da África do Sul, país tido como o que tem um dos movimentos mais atuantes de competência informacional de África.

Concluindo, consideramos que a base de dados da AJOL é representativa para o estudo de qualquer domínio de conhecimento na África subsaariana, porque engloba periódicos de países que, raramente, conseguem indexar suas revistas nas principais bases de dados internacionais.

A grande limitante é que não incorpora os periódicos dos países da África do Norte e nem consegue agregar outros periódicos de referência dos países da África subsaariana, em particular, os da África do Sul, país tido como o que tem um dos movimentos mais atuantes de competência informacional do continente africano. Portanto, estudos posteriores devem ser feitos em periódicos disciplinares indexados em outras bases para que se obtenha uma imagem mais completa das configurações dos estudos da competência informacional em todo o continente africano.

\section{REFERÊNCIAS}

AMERICAN ASSOCIATION OF SCHOOL LIBRARIANS. Standards for the 21st - century learner. Chicago, 2007. Disponível em: <http://www.ala.org/aasl/standards/permissions>. Acesso em: 28 set. 2018.

AMERICAN COLLEGE \& RESEARCH ASSOCIATION. Framework for Information Literacy for Higher Education, 2015. Disponível em: http://www.ala.org/acrl/standards/ilframework. Acesso em: 28 set. 2018.

ARAÚJ0, Carlos A. A. Bibliometra: evolução histórica e questões atuais. Em questão, v. 12, n. 1, p. 11-23, jan./jun. 2006. Disponível em: https://seer.ufrgs/EmQuestao/article/view/16/5. Acesso em: 23 dez. 2018.

ASSOCIATION OF COLLEGE \& RESEARCH LIBRARIES. Information Literacy Competency Standards for Higher Education, 2000. Disponível em: https://alair.ala.org/handle/11213/7668. Acesso em: 28 jun. 2018. 
CAPURRO, Rafael. Epistemología y ciencia de la información.Enlace: Revista Venezolana de Información, tecnología y conocimiento, v.4, n.1, 2007, p. 11-29. Disponível em: http://www.redalyc. org/articulo.oa?id=82340102. Acesso em: 28 set. 2018.

DECLARAÇÃO PRAGA. Rumo à uma sociedade albebetizada em informação, 2003. Disponível em: http://sol-e.com/plec/archivos/Docs_Bibliografias/Declaraci_Praga_castellano.pdf. Acesso em: 13 dez. 2018.

DERVIN, B.; NILAN, M. Information needs and uses. Annual Review of Information Science and Technology. NY: Knowledge industry publications, v.21, p. 03-33, 1986

DUDZIAK, Elisabeth Adriana. Information Literacy: princípios, filosofia e prática. Ciência da Informação, Brasília, v.32, n.1, p.23-34, jan./abr., 2003. Disponível em: Acesso em:

ELMBORG, James. Critical Information Literacy: Implications for Instructional Practice. The Journal of Academic Librarianship, v.32, n.2, p.192-199, 2006. Disponível em: https://www.sciencedirect. com/science/article/abs/pii/S0099133305001898. Acesso em: 11 jun. 2018.

ESTERHUIZEN, E. M; KUHN, R. CHELSA draft guidelines on Information Literacy: paving the way to a South African national framework? Innovation, v.4, 2010. Disponível em: https://www.ajol.info/index. php/innovation/article/view/63630. Acesso em: 05 out. 2018.

GUIMARÃES, José Augusto Chaves. Análise de domínio como perspectiva metodológica em organização da informação. Ciência da Informação, v.43, n.1, p.13-21, jan./abr., 2014. Disponível: http://revista.ibict.br/ciinf/article/view/1415/1593. Acesso em: 05 out. 2018.

GUPTA, Sushma; GUPTA, Davendra K. Development of Library and Information Science Education in Africa. The International Information \& Library Review, v. 29, n.1, p.95-107, 1997. Disponível em: https://www.sciencedirect.com/science/article/pii/S1057231797900333. Acesso em: 05 out. 2018.

HJØRLAND, Birger. Domain Analysis. Knowledge Organization, v.44, n.6, p.436-464, 2017.

HJØRLAND, Birger. Domain analysis in information science: eleven approaches-traditional as well as innovative. Journal of Documentation, v.58, n.4, p.422-462, 2002. Disponível em: https://www. emeraldinsight.com/doi/abs/10.1108/00220410210431136. Acesso em: 30 set. 2017.

HJØRLAND, Birger. Domain Analysis: A Socio-Cognitive Orientation for Information Science Research. Bulletin of the American Society for Information Science and Technology, 2007. Disponível em: https://onlinelibrary.wiley.com/doi/full/10.1002/bult.312. Acesso em: 28 set. 2018.

HJØRLAND, Birger; ALBRECHTSEN, Hanne. Toward a new horizon in information science: domain analysis. Journal of the American Society for Information Science, v.46, p.400-25, 1995. Disponível em: https://onlinelibrary.wiley.com/doi/abs/10.1002/(SICI)1097-4571(199507)46:6\%3C400::AIDASI2\%3E3.0.C0;2-Y. Acesso em: 23 jun. 2018.

KUHN, Thomas S. A estrutura das revoluções científicas. 5. ed. São Paulo: Editora Perspectiva S.A, 1997. 
LIMBERG, Louise; SUNDIN, Olof, TALJA, Sanna. Three theoretical perspectives on information literacy. Human It, v.11, n.2, p.93-130, 2012. Disponível em: https://pt.scribd.com/ document/138997016/Three-Theoretical-Perspectives-on-Information-Literacy-2012. Acesso em: 23 jun. 2017.

RABELLO, Rodrigo. A Ciência da Informação como objeto: epistemologias como lugares de encontro. Perspectivas em Ciência da Informação, v.17, n.1, p.2-36, jan./mar. 2012. Disponível em: http:// portaldeperiodicos.eci.ufmg.br/index.php/pci/article/view/1107/1012. Acesso em: 05 out. 2018.

SIMMONS, Michelle. Librarians as Disciplinary Discourse Mediators: Using Genre Theory to Move Toward Critical Information Literacy. Portal: Libraries \& the Academy, p.297-311, 2005. Disponível em: http://scholarworks.sjsu.edu/slis_pub/66/. Acesso em: 11 jun. 2018

TEWELL, Eamon. A decade of critical information literacy: a review of the literature. Communications in Information Literacy, v.9, n.1, p.24-43, 2015. Disponível em: http://www.comminfolit.org/index. php?journal=cil\&page=article\&op=view\&path\%5B\%5D=v9i1p24. Acesso em: 11 jun. 2018.

URIBE TIRAD0, Alejandro. La alfabetización informacional en las bibliotecas universitarias de Brasil: visualización de los niveles de incorporación desde la información publicada en sus sitios web.

Perspectivas em Ciência da Informação, v.17, n.1, p.134-152, jan./mar. 2012.

WANG, Li; BRUCE, Christine; HUGHES, Hilary. Sociocultural theories and their application in information literacy research and education. Australian Academic \& Research Libraries, v.42 n.4, p.296-308, 2011. Disponível em: https://www.tandfonline.com/doi/pdf/10.1080/00048623.2011.1072 2242. Acesso em: 05 out. 2018.

WERSIG, Gernot. Information science: the study of postmodern knowledge usage. Information Processing \& Management, v. 29, n. 2, p. 229-239, 1993. 